\title{
$\mathrm{EDXRF}$ 스펙트럼을 위한 효율적인 배경 모델링과 보정 방법
}

\section{( An Efficient Background Modeling and Correction Method for EDXRF Spectra )}

\author{
박 동 선, 자가디산 수카니아***, 진 문 용**, 윤 숙***** \\ ( Dong Sun Park, Sukanya Jagadeesan, Moonyong Jin, and Sook Yoon ${ }^{\odot}$ ) \\ 요 약
}

에너지 분산형 $\mathrm{X}$-선 형광(EDXRF) 분석에서 $\mathrm{X}$-선 스펙트럼에 존재하는 컨티넘(continuum)의 추정 및 제거는 필수적이다. 이를 위해 일반적으로 사용되는 알고리즘들은 많은 주의가 필요하며 복잡하다. 보통 이 알고리즘들은 제약적이거나 컨티넘의 데이터나 모양에 대한 가설을 필요로 한다. 본 논문에서는 제안된 에너지 분산형 $\mathrm{X}$-선 형광 스펙트럼을 위한 효율적인 배경 (background) 보정 방법은 배경 모델링과 배경 보정으로 구성된다. 이 방법은 스펙트럼에서 백그라운드영역과 피크영역을 구 분하는 기본 개념을 기반으로 하며 성능향상을 위하여 SNIP알고리즘을 사용한다. 스펙트럼으로부터 배경에 속하는 점들을 획 득한 후 이를 기반으로 곡선 근사화를 통해 배경을 모델링한다. 이후 획득된 배경 모델을 원 스펙트럼에서 뺌으로써 배경이 보정된 스펙트럼을 얻는다. 제안된 방법은 상대적으로 적은 사전 지식을 요구하면서 기존의 몇몇 방법들에 비해 우수한 결과 를 보여주었다.

\begin{abstract}
In energy dispersive $\mathrm{X}$-ray fluorescence analysis, the removal of the continuum on which the $\mathrm{X}$-ray spectrum is superimposed is one of the most important processes, since it has a strong influence on the analysis result. The existing methods which have been used for it usually require tight constraints or prior information on the continuum. In this paper, an efficient background correction method is proposed for Energy Dispersive X-ray fluorescence (EDXRF) spectra. The proposed method has two steps of background modeling and background correction. It is based on the basic concept which differentiates background areas from the peak areas in a spectrum and the SNIP algorithm, one of the popular methods for background removal, is used to enhance the performance. After detecting some points which belong to the background from a spectrum, its background is modeled by a curve fitting method based on them. And then the obtained background model is subtracted from the raw spectrum. The method has been shown to give better results than some of traditional methods, while working under relatively weak constraints or prior information.
\end{abstract}

Keywords: 신호 처리, 배경 보정, $\mathrm{EDXRF}$ 분석기, SNIP, 보간법

* 정회원, ${ }^{* *}$ 학생회원, 전북대학교 전자공학부

(Division of Electronics Engineering, Chonbuk National University)

**** 정회원, Dept. of Electronics and Communication Eng., Mahendra College of Engineering, Tamil Nadu, India

**** 정회원, 목포대학교 멀티미디어공학과

(Dept. of Multimedia Eng., Mokpo National University)

* 정회원, 전북대학교 IT융합연구센터

(IT Convergence Research Center, Chonbuk National University)

(c) Corresponding Author(E-mail: syoon@mokpo.ac.kr)

※ 본 연구는 교육과학기술부와 한국연구재단의 지역혁신인력양성사업으로 수행된 연구결과임.

※ 이 논문은 2013 년도 정부(교육부)의 재원으로 한국연구재단의 지원을 받아 수행된 기초연구사업임

(No. 2013R1A1A2013778).

접수일자: 2013년5월15일, 수정완료일: 2013년7월24일 


\section{I. 서 론}

에너지 분산형 $\mathrm{X}$-선 형광 $(\mathrm{EDXRF})$ 기술은 물질의 비파괴 다중원소 분석에 강력한 기술로 지난 몇 년 동 안 정량 분석을 위한 여러 방법들이 개발되어 왔다. $\mathrm{EDXRF}$ 스펙트럼은 물질의 화학 및 물리적 특성들을 직간접적으로 측정하는 데 사용된다. 측정된 스펙트럼 은 물질의 원래 정보인 피크 정보이외에 컨티넘 (continuum)이라 불리는 배경(background) 및 잡음 (noise)등의 원치 않는 정보를 포함할 수 있으며 스펙트 럼 변화에 많은 영향을 주는 이러한 컨티넘들은 계측기 보정(instrument calibration)이나 스펙트럼 정보의 양자 화에서 문제를 야기할 수 있어 물질의 정확한 분석을 방해한다. 이에 스펙트럼 데이터로부터의 배경 제거는 많은 관심을 받고 있다. 배경은 $\mathrm{X}$-선 형광 $(\mathrm{EDXRF})$ 분석에서 중요한 부분으로 이를 제거하는 것이 스펙트 럼 분석의 첫 번째 전처리 단계이며 이 결과는 이후의 분석 단계에 많은 영향을 미친다 ${ }^{[1][2]}$. 그러나 다양한 원 인들로부터 발생하는 배경과 잡음은 주어진 $\mathrm{EDXRF}$ 스 펙트럼 데이터로부터 제거하기 쉽지 않으며 배경의 경 우 스펙트럼 샘플에 따라 변하기 때문에 제거하기가 어 렵고 이를 해결하기 위한 몇 가지 방법들만이 적절한 결과를 보여주고 있다.

배경 제거를 위한 일반적인 방법들에는 다항식 근사 화 방법(polynomial fitting method) ${ }^{[3]}$, 반복 방법 (iterative method) ${ }^{[4 \sim 5]}$ 과 $\mathrm{SNIP}$ (Statistics Sensitive Nonlinear Iterative Peak-Clipping Algorithm) ${ }^{[6 \sim 10]}$ 등이 있다. 다항식 근사화 방법은 스펙트럼에서 적절한 배경 점들을 선택해야 하며 선택된 배경 점들은 배경이라고 여겨지는 곡선에 맞춰 진다. 그러므로 적절한 배경 점 을 잘 선택하는 것은 다항식 근사화 방법에서 매우 중 요한 단계이며 보통 자동 및 수동으로 선택되기 때문 에 다항식 근사화 방법에 의해 추정된 배경은 사용자 가 조정할 수 있는 매개 변수에 의해 영향을 받을 수 있다. SNIP 방법은 사용이 간편하기 때문에 많은 관심 을 받고 있다. SNIP 방법을 이용하면 개체 (피크)가 위 치한 지역의 실제 폭을 알 수 있을 때 피크 부근에서 완전히 배경을 제거 할 수 있으며 정확하게 폭이 계산 될수록 배경은 보다 정확하게 제거가 될 수 있다. 하지 만 SNIP 방법은 실제 폭을 정확하게 얻는 것이 어렵기 때문에 제약이 있으며 많은 시간 소요를 요구한다. 본
논문에서는 개선된 배경 제거 방법을 보이고 이 방법 의 정확성과 신호의 잡음 성분과의 연관성에 대해서 살펴본다. 이를 위하여 위에서 설명한 기존 방법보다 보다 효율적으로 배경을 제거하는 방법으로 배경 모델 링 및 배경 보정의 두 단계를 가지는 간단한 배경 추 정방법을 제안한다. 피장에서는 관련 연구를 살펴보고 제안된 방법과 절차의 핵심 개념을 설명한다. 피장에서 는 실험결과에 대하여 논하고 마지막 장에서는 결론을 제시한다.

\section{II. 본 론}

\section{1. 관련 연구}

많은 관심을 받고 있는 사용이 간편한 SNIP 방법은 채널 $y_{i}$ 와 $y_{i}$ 의 이웃 채널들을 비교하여 스펙트럼에서 빠르게 변화하는 부분을 제거하는 것을 기반으로 한다. Clayton등은 채널 $y_{i}$ 와 식 (1)의 $y_{i}$ 의 두개의 이웃들의 평균을 비교하는 방법을 제안 하였다 ${ }^{[10]}$.

$$
m_{i}=\frac{y_{i-1}+y_{i+1}}{2}
$$

$y_{i}$ 가 $m_{i}$ 보다 작으면 채널 $y_{i}$ 는 $m_{i}$ 로 교체된다. 이 변 환이 모든 채널에서 한 번 실행되면 피크들의 높이는 약간 감소하는 반면에 스펙트럼의 나머지 부분은 거의 그대로 유지되는 것을 관찰할 수 있다. 이를 반복함에 따라, 피크들은 점차 스펙트럼에서 "깎여 나가게 (stripped)" 된다. 이 방법은 국소 최소점(local minimum)을 연결하는 경향이 있기 때문에 컨티넘의 국소적인 변동에 매우 민감하다. 이를 보완하기 위하여 깎는 작업(stripping) 전에 컨티넘 평활화를 먼저 적용 할 수 있으며 이는 반복 횟수를 줄일 수 있다. 컨티넘을 평활화하기 위해 주로 식(2)와 같이 데이터에 로그나 제곱근을 취한다.

$$
y_{i}^{\prime}=\log \left(y_{i}+1\right) \text { 또는 } y_{i}^{\prime}=\sqrt{y_{i}}
$$

깎는 작업 후 컨티넘 모양은 역 변환을 적용하여 얻 어진다. 이 방법의 가장 큰 단점은 부분적으로 중첩되 어 있는 피크들이 중첩되어 있지 않은 하나의 피크보다 제거하는 데 훨씬 오래 걸려 많은 반복 후에 피크의 아 랫부분(base)이 험프(hump)로 남게 되는 것이다. SNIP 
방법은 개체 (피크)가 위치한 지역의 실제 폭을 알 수 있을 때 피크 부근에서 완전히 배경을 제거할 수 있으 며 정확하게 폭을 계산할수록 보다 정확한 배경제거가 될 수 있다 ${ }^{[6]}$. 하지만 SNIP 방법은 실제 폭을 정확하 게 얻는 것이 어렵기 때문에 제약이 있으며 많은 시간 소요를 요구한다.

배경 제거 방법으로 $\mathrm{SNIP}$ 을 이용한 실험 스펙트럼에 정량 분석을 수행한 결과는 표 1 과 같으며 성분들의 농 도값 추정을 보여준다. 윈도우의 크기에 따라 배경 제 거 결과가 달라지므로 추정된 농도도 달라짐을 알 수 있다. 실험으로부터 원소의 농도 추정값이 원소의 실제 농도값에 충족할 만한 결과를 보여주지 못하지만 윈도 우 크기가 45 일 때 원소의 실제 농도에 가장 가까운 결 과를 보인다는 결론에 도달 할 수 있다.

수학적 형태학(mathematical morphology)은 영상처 리에 대한 비선형 접근법으로서 이 분야에서 신호 특성 들을 보존하면서 잡음 제거를 하는데 강건한 성능을 보 여 준다. 수학적 형태학은 형상 정보를 포함한 구조적 요소(structural element)라 불리는 하나 이상의 서로 다른 집합으로 이루어진 신호 집합의 상호 작용으로 볼 수 있다. 이 상호 작용은 원본 데이터를 사용자를 위해 더 많은 표현이 의도된 새로운 형태로 변경한다. 형태 학적 연산자를 스펙트럼 데이터 같은 일차원 신호에 적 용하기 쉽다 ${ }^{[10 ~ 12]}$.

형태학적 언어는 두 가지 연산, 팽창과 침식을 기반 으로 한다. $\mathrm{X}$-선 스펙트럼은 음의 피크들을 포함하지 않기 때문에 컨티넘을 제거하는데 열림 연산만을 필요 로 한다 ${ }^{[14]}$. 구조 요소를 적용하여 컨티넘 추정치를 얻 고 원래의 스펙트럼으로부터 이 컨티넘의 추정치를 뺀

표 1. 원소의 실제 농도값과 SNIP방법의 윈도우 크기 에 따른 원소의 추정 농도값

Table 1. Actual concentration level of elements of the standard sample and concentration levels estimated in SNIP method with respect to the window size.

\begin{tabular}{|c|r||c|c|c|c|c|c|}
\hline \multirow{2}{*}{ 원소 } & \multicolumn{1}{|c||}{ 실제 } & \multicolumn{7}{|c|}{ 윈도우 크기 } \\
\cline { 4 - 8 } & 농도값 & 25 & 30 & 35 & 40 & 45 & 50 \\
\hline \hline $\mathrm{Cr}$ & 1003 & 940 & 944 & 945 & 943 & 942 & 906 \\
\hline $\mathrm{Br}$ & 1100 & 1137 & 1142 & 1189 & 1191 & 1164 & 1134 \\
\hline $\mathrm{Cd}$ & 300 & 271 & 277 & 303 & 301 & 248 & 237 \\
\hline $\mathrm{Hg}$ & 1100 & 1082 & 1097 & 1099 & 1101 & 1093 & 1092 \\
\hline $\mathrm{Pb}$ & 1199 & 1321 & 1310 & 1379 & 1366 & 1284 & 1300 \\
\hline
\end{tabular}

후 결과를 얻을 수 있지만 피크 크기가 다소 작아진다. 이를 보완하기 위해 피크의 극점들이 결정되면 선형 또 는 고차 보간을 할 수 있다. 이 방법은 $\mathrm{SNIP}$ 과 같은 방 법에 공통적으로 사용되는 반복을 필요로 하지 않기 때 문에 빠르다. 또한 이 방법은 채널, 즉 에너지에 따라 형태학적 연산의 특성을 변경하기 쉽기 때문에 다양한 목적으로 사용할 수 있다. 하지만 백그라운드 추정에 대한 정확도는 다른 방법에 비해 떨어진다.

\section{2. 제안된 방법}

이 절에서는 제안된 배경 보정 방법을 설명한다. 제 안된 방법이 스펙트럼에 어떻게 작동하는지 보이기 위 해 두 부분으로 나누어 설명한다. Part I은 스펙트럼을 영역으로 분리하고 각 영역의 표준 편차를 찾는다. Part II에서는 스펙트럼을 작은 지역 윈도우로 나누고 윈도 를 기반으로 각 점이 배경 영역에 속하는지 피크 영역 에 속하는지를 검사하여 배경 점들을 찾는다. 마지막으 로 찾은 배경에 속하는 점들을 이용하여 곡선 근사화를 통하여 배경 곡선을 얻은 후 이를 원 스펙트럼에서 뺀 다. 그림 1은 블록도를 이용하여 제안된 방법의 단계별 절차를 보여준다.

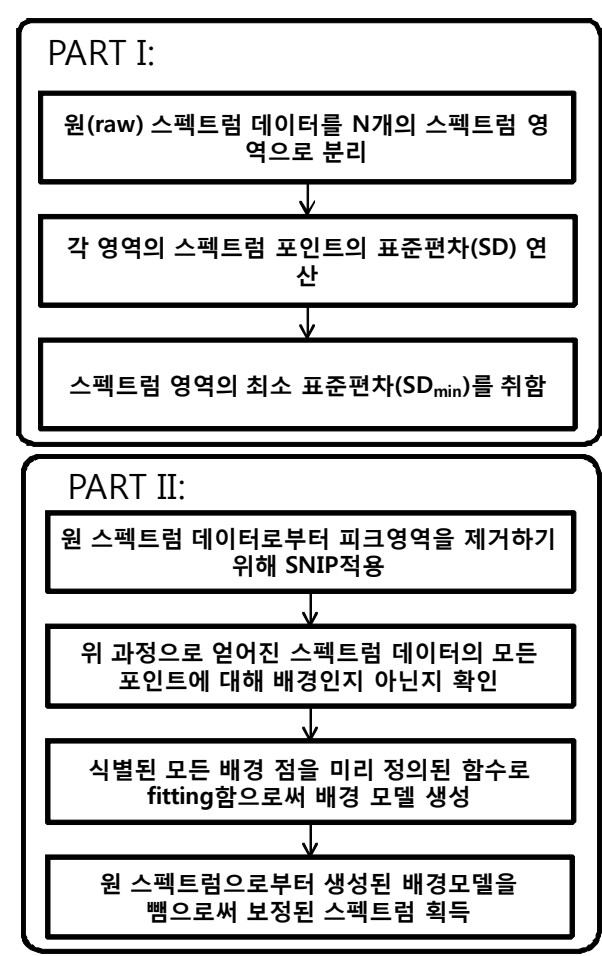

그림 1. 제안된 알고리즘을 위한 블록도

Fig. 1. Block diagram for proposed algorithm. 
앞에서 언급 한 바와 같이 배경 보정 방법은 두 부분 으로 동작한다. 첫 번째 부분은 전체 스펙트럼을 $N$ 개의 스펙트럼 영역으로 분할하여 각 영역의 스펙트럼의 표 준 편차 $(S D)$ 를 찾는다. 그리고 각 영역의 표준편차 중 최소값 $\left(S D_{\min }\right)$ 을 구한다. 여기에서 영역의 표준편차들 중 최소값을 취한 이유는 스펙트럼 영역 중 피크들과 배경을 포함하지 않는 영역이 적어도 하나는 있다라는 가정에서 출발하였다. “배경”의 궁극적인 정의는 “피크 를 포함하지 않는" 것이기 때문에 피크 영역을 찾기 위 한 개념을 배경을 찾는 것에 사용할 수 있는 것은 당연 하다. 문제는 배경으로 선택된 점이 피크 영역에 있을 때 발생할 수 있다. 배경을 계산하기 위해 선택된 점들 이 피크영역에 위치해 있다면 배경이 너무 클 것이기 때문이다. 이 문제를 해결하기 위한 방법으로 스펙트럼 으로부터 피크 영역을 제거하기 위하여 SNIP 알고리즘 을 적용한다.

두 번째 부분에서는 피크 부분이 스펙트럼에서 제거 된다. SNIP을 원 스펙트럼에 적용한 후 얻어진 스펙트 럼을 폭이 $w$ 인 작은 윈도우들로 나누고 각 윈도우의 중심점이 배경에 속하는지 아닌지 결정해야 한다. 이 윈도우에서 스펙트럼에 포함되는 신호 범위는 윈도우 내 최대값과 최소값의 차이로 구한다. 이 범위가 최소 표준 편차인 $S D_{\min }$ 보다 작으면 점은 '배경 점'으로 간 주되고 크거나 같은 경우 '피크 점'으로 간주된다. 식별 된 모든 배경 점을 통해 배경은 미리 정의된 함수형태 로 근사화되며 실험에서는 근사화 함수로 삼차 스플라 인 함수를 사용하였다.

\section{III. 실 험}

이 장에서는 제안된 알고리즘을 $\mathrm{EDXRF}$ 스펙트럼에 적용한다. 그림 3은 $\mathrm{iEDX}-100 \mathrm{~A} \mathrm{EDXRF}$ 분석으로부터 얻어진 그림 2의 Plastic PE 샘플의 원 스펙트럼(raw spectrum) 데이터를 보여주고 있다. $\mathrm{iEDX}-100 \mathrm{~A}$ $\mathrm{EDXRF}$ 장비의 기술적 규격을 살펴보면 $50 \mathrm{kVp}, 50 \mathrm{~W}$, $\mathrm{X}$-ray Tube Excitation 소스로부터 얻어진 Rh Target 그리고 $\mathrm{Si}$-Pin Diode(Peltier System) 검출기를 사용하 며 $\mathrm{Mn}-\mathrm{Ka}(5.9 \mathrm{eV})$ 에서 $149 \mathrm{eV}$ 의 에너지 분해능(Energy Resolution)을 가진다. 실험에서 사용된 분석 물질인 $\mathrm{PE} \mathrm{High} \mathrm{샘플에} \mathrm{존재하는} \mathrm{원소들과} \mathrm{Plastic} \mathrm{PE} \mathrm{표준}$ 시편의 실제 원소 농도는 표 2 와 같다.

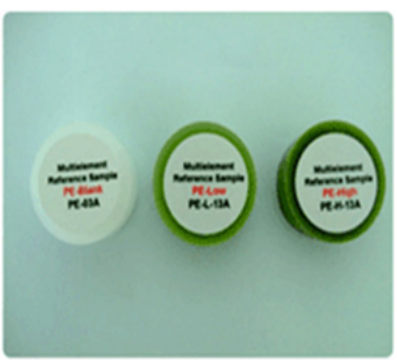

그림 2. Plasitc PE 표준 시편

Fig. 2. Plastic PE Standard Sample.

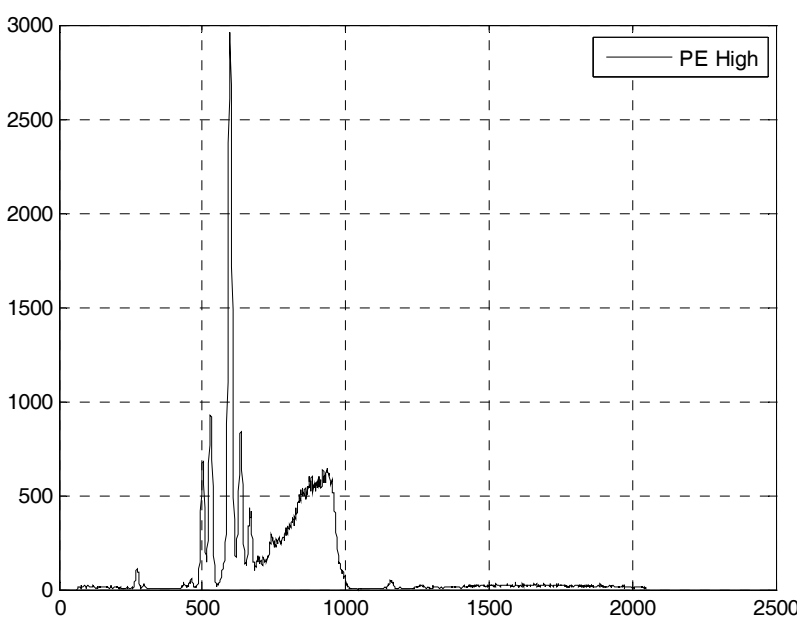

그림 3. IEDX-100A EDXRF 분석으로부터 얻어진 Plastic $\mathrm{PE}$ 샘플의 원 스펙트럼 데이터

Fig. 3. Raw spectrum from a iEDX-100A EDXRF analysis of a Plastic PE sample.

표 2. Plastic PE 표준 시편의 원소의 실제 농도

Table 2. Actual concentration level of elements of Plastic PE standard sample.

\begin{tabular}{|c|c|c|}
\hline 원소 & 기호 & 실제 농도값(ppm) \\
\hline 크롬 & $\mathrm{Cr}$ & 1003 \\
\hline 브롬 & $\mathrm{Br}$ & 1100 \\
\hline 카드뮴 & $\mathrm{Cd}$ & 300 \\
\hline 수은 & $\mathrm{Hg}$ & 1100 \\
\hline 납 & $\mathrm{Pb}$ & 1199 \\
\hline
\end{tabular}

제안된 알고리즘에 따라 먼저 원 스펙트럼을 $\mathrm{N}$ 개의 스펙트럼 영역으로 나누고 (본 논문에서는 $N=32$ ), 각 스펙트럼 영역의 스펙트럼 포인트의 $S D$ 를 찾고 이 중 최소값을 $S D_{\mathrm{min}}$ 으로 취한다. 그림 4 와 같이 본 논 문에서 사용된 $\mathrm{PE} \mathrm{High} \mathrm{샘플의} \mathrm{스펙트럼의} S D_{\mathrm{min}}$ 는 1.6 이다.

다음으로 SNIP 알고리즘을 원스펙트럼 데이터에 적 용함으로써 추정되는 피크 영역을 제거한다. 피크가 제 거된 스펙트럼 데이터를 너비 $w$ 의 작은 윈도우로 나누 


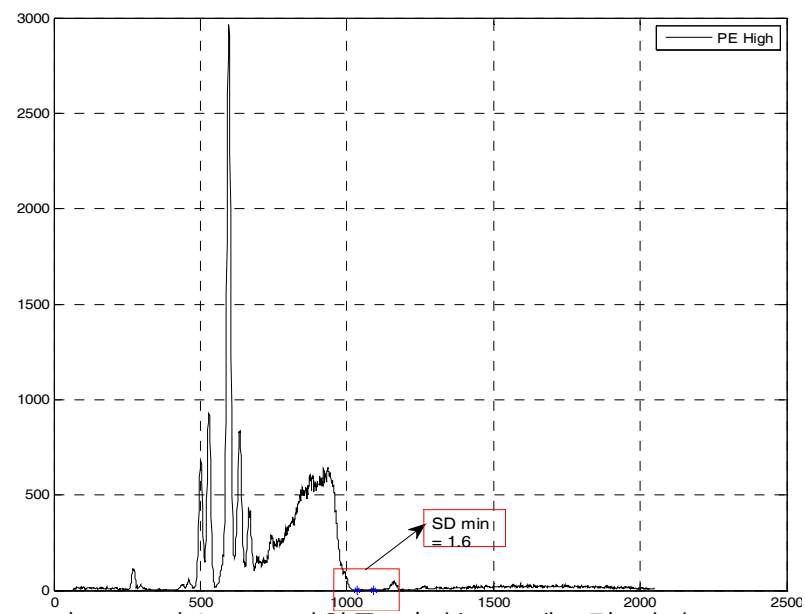

그림 4. 최소 표준편차를 가지는 스펙트럼 ${ }^{2000}$ 영역

Fig. 4. Region with the Minimum SD of the Raw Spectrum.

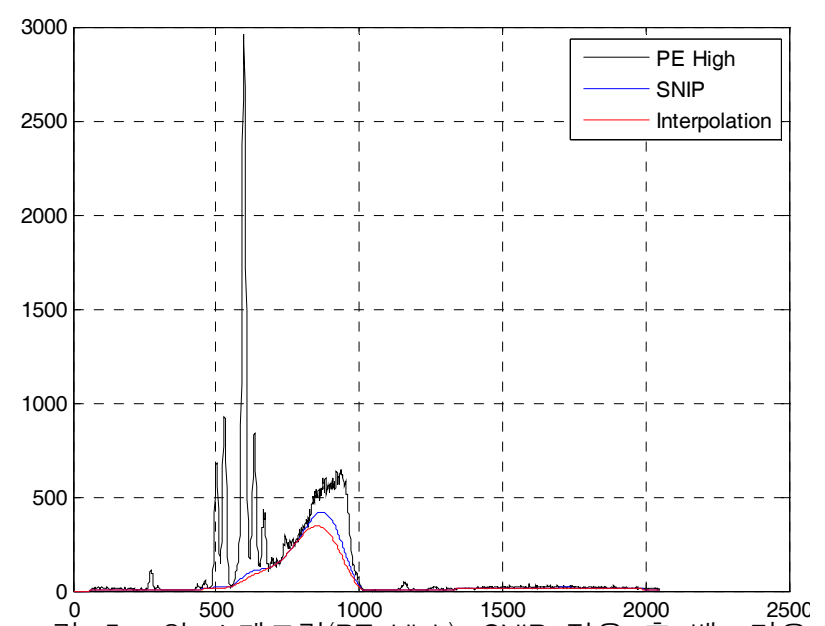

그림 5. 원 스펙트럼(PE High), SNIP 적용 후 백그라운 드 모델(SNIP)과 제안된 방법 적용 후 백그라운 드 모델(Interpolation)

Fig. 5. EDXRF raw spectrum, background model from SNIP method, and background model from the proposed method.

어 (본 논문에서는 $w=30$ ), 스펙트럼상의 모든 점을 ‘배경 점’인지 또는 '피크 점'인지 평가한다. 너무 큰 윈 도우의 크기 $w$ 는 먼 거리의 점들의 배경 여부를 판단하 는데 기여도를 높이는 효과가 있으므로 적절한 크기를 사용해야 한다. 추출된 '배경 점‘들과 이들의 근사화를 통해 배경을 모델링한 후 원 스펙트럼 데이터로부터 배 경이 제거된 스펙트럼을 얻기 위해 뺄셈을 취한다.

그림 5는 제안된 알고리즘과 SNIP 알고리즘을 통해 얻어진 배경 모델을 같이 보여 주고 있다. 그리고 Plastic PE 샘플의 원 스펙트럼과 이를 제안된 알고리 즘을 통해 배경 신호를 보정한 스펙트럼은 그림 6 과 같

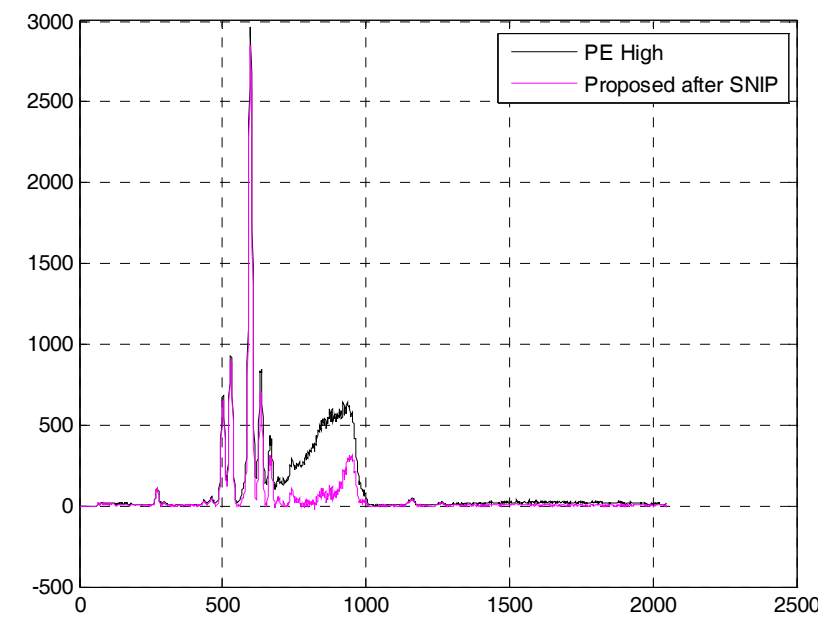

그림 6. 원 스펙트럼(PE High)와 제안된 방법에 의한 배 경 보정 스펙트럼

Fig. 6. Raw spectrum and its spectrum after background correction by the proposed algorithm.

표 3. 원 스펙트럼(PE High)의 배경 보정 후 얻어진 스펙트럼을 정량 분석한 후 획득한 원소의 농 도와 실제 농도와의 비교

Table 3. Comparison between the actual concentration levels and concentration levels of elements obtained by Smart Ray software after removing the background.

\begin{tabular}{|c|c|r||r|r|r|}
\hline 원소 & 기호 & $\begin{array}{c}\text { 실제 } \\
\text { 농도값 }\end{array}$ & $\mathrm{SNIP}$ & 모폴로지 & $\begin{array}{c}\text { 제안된 } \\
\text { 방법 }\end{array}$ \\
\hline \hline 크롬 & $\mathrm{Cr}$ & 1003 & 942 & 918 & 950 \\
\hline 브롬 & $\mathrm{Br}$ & 1100 & 1164 & 1030 & 1152 \\
\hline 카드뮴 & $\mathrm{Cd}$ & 300 & 248 & 256 & 281 \\
\hline 수은 & $\mathrm{Hg}$ & 1100 & 1093 & 731 & 1083 \\
\hline 납 & $\mathrm{Pb}$ & 1199 & 1284 & 438 & 1213 \\
\hline
\end{tabular}

다. 제안된 방법을 평가하기 위해 ISP CO., LTD로부터 제공된 Smart Ray 소프트웨어를 사용해 테스트하였다. $\mathrm{SNIP}$ 을 이용하여 배경을 보정한 스펙트럼 ${ }^{[10]}$, 모폴로지 를 이용하여 배경을 보정한 스펙트럼 ${ }^{[11]}$, 그리고 제안된 방법을 이용하여 배경을 보정한 스펙트럼을 각각 Smart Ray 소프트웨어의 입력으로 주어 원소들의 정량 분석을 실시하였으며 그 결과는 표 3 과 같다.

세 가지 방법을 적용한 후 얻어진 스펙트럼을 정량 분석한 후 획득한 원소의 농도를 실제 농도와 비교했을 때 제안된 방법의 결과가 가장 좋은 성능을 보임을 알 수 있다. 제안된 방법의 경우 수은을 제외한 모든 원소 에서 가장 근접한 농도 추정치를 보였으며 실제 농도값 과 이들의 추정치간의 평균 차이를 살펴보면 $\mathrm{SNIP}$ 의 방법, 모폴로지 방법, 제안된 방법에 대해 각각 약 
$7.4 \%, 25.3 \%, 3.8 \%$ 의 차이를 보였다. 또한 제안된 방법 은 SNIP만 적용했을 때보다 계산량은 증가되지만 일반 적으로 $\mathrm{SNIP}$ 만을 적용할 때 요구되는 피크 너비와 같 은 정확한 사전 정보에 의한 파라미터 설정에 자유롭다 라는 장점을 지닌다.

\section{IV. 결 론}

본 논문에서 제안된 배경 보정 방법은 효과적이며 사 용자에게 적당한 입력 파라미터값만을 요구한다. 피크 의 실제 너비와 같이 상대적으로 정확한 사전 정보를 요구하는 SNIP알고리즘이나 다른 기존의 방법들과 비 교했을 때 제안된 배경 보정 방법은 적절한 정도의 정 보에서 동작하므로 보다 자기-적응적이고 사용자에 의 한 조정 파라미터에 보다 자유롭다. 그러나 최적의 배 정 보정 방법을 위한 문제는 여전히 남아있다. 향후 $\mathrm{EDXRF}$ 스펙트럼 분석 프로세스의 성능 향상을 위해 보다 나은 배경 묘사 방법을 연구하고 다양하고 많은 스펙트럼을 대상으로 배경 보정 방법을 개선하고 검증 하여야 한다.

\section{REFERENCES}

[1] G. Liangquan, Z. Sichun, In-situ X Radiation Sampling Technique, Proc. Of SiChuan technology publish, pp. 131-149, ISBN 7-5364-3693-9, 1997.

[2] 장인걸, 이재경, 정진균, "보조필터를 이용한 가준 치 보간방법," 대한전자공학회논문지-SP, 제 48 권 SP편, 제3호, 119-124쪽, 2011년 5월

[3] P. Junfeng, Gamma Spectra Processing, Proc. Of Shanxi technology publish, pp. 696-703, ISBN 75369068, 1990

[4] M. H. Zhu, L. G. Liu, Y. S. Cheng, T. K. Dong, Z. You, A. A. $\mathrm{Xu}$, "Iterative estimation of the background in noisy spectroscopic data," Nucl Instrum Meth A, vol. 602, no. 2, pp. 597-599, April 2009

[5] Z. Meng-Hua, L. Liang-Gang, X. A. M. Tao., "Automatic Estimation of Peak Regions in Gamma-Ray Spectra Measured by NaI Detector ," Chinese Physics Letters, vol. 25, no. 11, pp. 3942-3945, November 2008.

[6] M. Morhac, J. Kliman, V. Matousek, M. Veselsky, I. Turzo. "Background elimination methods for multidimensional coincidence 8 -ray spectra," Nucl. Instrum. Meth A, vol. 401, no.1, pp.113-132, December 1997.

[7] M. Morhac, V. Matousek. "Peak clipping algorithms for background estimation in spectroscopic data ," Appl. Spectrosc. 2008, vol. 62, no. 1, pp. 92-106, January 2008.

[8] M. Morhac. "An algorithm for determination of peak regions and baseline elimination in spectroscopic data," Nucl. Instrum. Meth A, vol. 600, no. 2, pp. 478-487, March 2009.

[9] R. Fischer, V. Dose, K. M. Hanson, W. von der Linden. "Bayesian background estimation," AIP Conf. Proc., vol. 567, pp. 193-212, August 1999.

[10] Ryan CG, Clayton E, Griffin WL, Sie SH, Cousens DR. "SNIP, a statistics-sensitive background treatment for the quantitative analysis of PIXE spectra in geoscience applications," Nucl. Instrum. Methods B, vol. 34, no. 3, pp. 396-402, September 1988.

[11] P. E. Trahanias, "An approach to QRS complex detection using mathematical morphology," IEEE Trans. Biomed. Eng., vol. 40, no. 2, pp. 201-205, February 1993.

[12] C. H. H. Chu and E. J. Delp, "Impulsive noise suppression and background normalization of electrocardiogram signals using morphological operators," IEEE Trans. Biomed. Eng., vol. 36, pp. 262-273, 1989.

[13] J. P. Serra, Image Analysis and Mathematical Morphology, New York:Academic, 1982.

[14] Antonio Brunetti, "Removal of the Continuum of X-Ray Spectra Using Morphological Operators" IEEE Trans. Nuclear Science, vol. 45, no. 5, pp. 2281-2287, May 1998. 
저 자 소 개

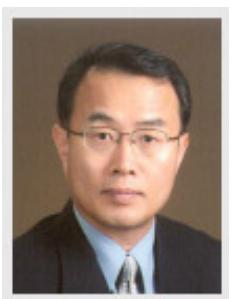

박 동 선(정회원)

1979년 고려대학교

전자공학과 학사 졸업.

1984년 미국 Missouri대 공학석사.

1991년 미국 Missouri대 공학박사.

1991년 현재 전북대학교 전자공학부 교수 <주관심분야 : 신경망, 패턴인식, 영상처리>

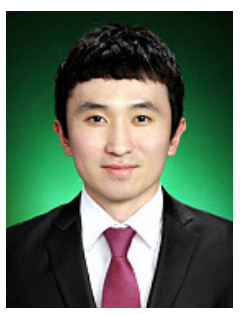

진 문 용(학생회원)

2012년 전북대학교

전자공학과 학사졸업.

2012년 현재 전북대학교

전자공학과 석사과정.

<주관심분야 : 신호처리, 컴퓨터비전, 패턴인식>

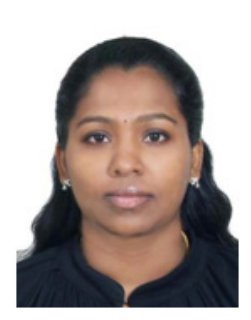

자가디산 수카니아(정회원)

2002년 인도 Government College of Engineering 학사 졸업.

2012년 전북대학교 전자공학과 공학석사.

2012년 현재 조교수 Mahendra College of Engineering, India <주관심분야 : 신호처리, 의료영상처리>

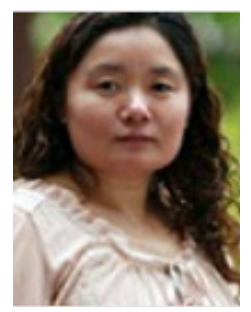

윤 숙(정회원)

1993년 전북대학교

정보통신공학과 학사 졸업.

1995년 전북대학교

정보통신공학과 공학석사.

2003년 전북대학교

전자공학과 공학박사.

2006년 현재 목포대학교

멀티미디어공학과 부교수

<주관심분야 : 영상처리, 멀티미디어, 패턴인식> 